\title{
Complexidade em Saúde da Família e formação do futuro profissional de saúde
}

Rodrigo Otávio Moretti-Pires ${ }^{1}$

MORETTI-PIRES, R. O. Complexity in Family Healthcare and the training of future healthcare professionals. Interface - Comunic., Saude, Educ., v.13, n.30, p.153-66, jul./set. 2009.

The characteristics of the Unified Health System (SUS) and the Family Healthcare Strategy (ESF) bring them close to complex thought, a term that refers to the theoretical and epistemological framework rather than to an adjective describing phenomena with multiple features. Indications of inadequacy in the training of healthcare professionals, for them to work within family healthcare, led to a proposal to survey the training of these professionals for the expanded approach to healthcare implicated in SUS/ESF. Focus groups among undergraduate nursing, medical and dental students at the Federal University of Amazonas were conducted, with analysis from a hermeneutic-dialectic perspective. The data indicated that the training for these three professions was reductionist and biomedical, focusing on individual work rather than on multi-professional teamwork. This is an inadequate framework for SUS/ESF, for which professional action focusing on the complexity of the socioeconomic and anthropological context of the system's users is recommended.

Keywords: Training of healthcare human resources. Primary healthcare. Complexity theory.
As características do Sistema Único de Saúde (SUS) e da Estratégia de Saúde da Família (ESF) os aproximam do pensamento complexo, termo que não se refere à adjetivação de fenômeno de aspectos múltiplos, e sim ao marco teórico e epistemológico. Indícios de inadequação da formação dos profissionais de saúde para a atuação em Saúde da Família levaram a proposta de levantar a formação desses profissionais para a abordagem ampliada de saúde implicada no SUS/ESF. Foram realizados grupos focais com acadêmicos de Enfermagem, Medicina e Odontologia da Universidade Federal do Amazonas, analisado sob a perspectiva hermenêutica dialética. Os dados apontaram para a formação reducionista/biomédica nas três profissões assim como o foco no trabalho individual, e não em equipe multiprofissional, quadro inadequado ao SUS/ESF, que preconiza atuação profissional focada na complexidade do entorno sócioeconômico e antropológico dos usuários do sistema.

Palavras-chave: Formação de recursos humanos em saúde. Atenção primária à saúde. Teoria da complexidade.
${ }^{1}$ Departamento de Saúde Pública, Centro de Ciências da Saúde, Universidade Federal de Santa Catarina. Campus Universitário, Trindade, Florianópolis, SC, Brasil. 88.040-900. rodrigomoretti@ccs. 


\section{Introdução}

A realidade é complexa e, como ser imerso na realidade, o ser humano traz em si a complexidade. Este é o ponto de partida para o presente trabalho: a complexidade implicada na interação entre ser humano e arcabouço/mundo em que se insere. Ressalta-se, no entanto: é recorte de um contexto particular, pretendendo que se articulem os pressupostos da Estratégia de Saúde da Família (ESF) ao processo formal de profissionalização dos acadêmicos enfermeiros, médicos e odontólogos.

No presente trabalho o termo "complexo" não se refere à adjetivação de determinado fenômeno de aspectos múltiplos, mas sim à "complexidade" enquanto referencial teórico-filosófico e epistemológico. O complexo origina-se do emaranhado de eventos, interações, retroações, incidentes, que constituem o mundo dos fenômenos (Morin, 1996). Não pressupõe eliminação da simplificação, mas uma perspectiva integradora, assumindo lacunas que surgem entre as explicações do paradigma da simplificação quando este não se mostra suficiente perante dificuldades empíricas e dificuldades lógicas. As primeiras se referem ao fato de que tudo está em relação no Universo, enquanto a última "[...] aparece quando a lógica dedutiva se mostra insuficiente para dar uma prova num sistema de pensamento e surgem contradições que se tornam insuperáveis" (Morin, 1996, p.275). Deve-se ressaltar que o pensamento complexo não tem pretensão de ser completude (Morin, 2001, 1996).

As disciplinas - categoria organizacional do conhecimento científico - se pautam na especialização do trabalho. São delimitadas em si mesmas e revestem-se de autonomia nas suas técnicas de condução, elaboração e utilização, circunscrevendo-se à(s) teoria(s) a que se refere(m). Paradoxalmente, "o homem é simultaneamente biológico e não-biológico" (Morin, 1996, p.281) e a segregação de ambas as dimensões "[...] nos impõe sempre uma visão mutilada. Mas, além disso, o homem não é somente biológico-cultural. É também espécie-indivíduo, sociedade-indivíduo; o ser humano é de natureza multidimensional" (Morin, 1996, p.282).

Inicialmente como Programa, a ESF originou-se na reformulação das prioridades do Ministério da Saúde em relação à Atenção Primária, sendo proposta como caminho para reorganização da atenção à saúde no Brasil, com vistas a tornar efetivo o Sistema Único de Saúde (SUS) (Mendonça, Vasconcellos, Vianna, 2008). Compromete-se em prestar atenção pautada no atendimento integral, contínuo, com equidade e resolutividade, por meio de prática humanizada, e desenvolver ações de prevenção e promoção de Saúde.

Parte de um processo de trabalho em equipe multiprofissional, que deve: conhecer as famílias do território sob sua abrangência; identificar problemas de saúde e situações de risco desta comunidade; exercer planejamento local com base e imerso na realidade que planeja, pautando-se no rompimento da lógica biomédico-curativo-medicalizada, para um enfoque em ações educativas e intersetoriais, fazendo valer o princípio da integralidade na atenção, em um continuum com os demais níveis de assistência, buscando criar vínculos entre os profissionais e usuários, por intermédio da corresponsabilização na resolução dos problemas de saúde (Brasil, 2007).

O usuário deve ser ressignificado no processo de trabalho, dimensão complexa ao dar ênfase à coparticipação no planejamento da assistência, com enfoque na valorização de saberes e do entorno sociocultural, em um gradativo processo de horizontalização e humanização da relação profissional de saúde-usuário (Brasil, 1997).

Evidencia-se, assim, a abordagem ampliada da atenção em saúde e da complexidade inerente, podendo ser considerado um modelo contra-hegemônico ao modelo flexneriano/biomédico, que valoriza apenas saberes oriundos da academia e a supremacia/dominação do poder do profissional sobre a saúde do usuário, em que há ênfase no fenômeno biológico, distanciando-se das dimensões sociais, psicológicas e comportamentais implicadas na doença. A concepção mecanicista em saúde Ihe é inerente, em que o corpo é como uma máquina composta por partes inter-relacionadas e a doença reduz-se à irregularidade no processo de funcionamento, valorizando-se a formação clínica e subespecialidades, deixando à margem o aspecto subjetivo e relacional do encontro com o paciente (Marco, 2006; Koifman, 2001).

Com a implementação da Saúde da Família, o discurso político governamental se alterou com vistas a reorientar o recurso humano em saúde, em termos de capacitação para a integralidade e nova prática no SUS não apenas no contexto do serviço, mas também na formação dos futuros profissionais 
já no âmbito dos cursos de Enfermagem, Medicina e Odontologia (Moretti-Pires, 2008). Cabe ressaltar que este processo não se deu simplesmente por opção política dos governos, mas sim em virtude de necessidades concretas de assistência à saúde da população brasileira frente ao dever constitucional do Estado em relação à saúde de todos os cidadãos.

Mesmo com estes esforços, ainda foi mantido o modelo universitário tradicional focado na atenção curativo-individual, desconsiderando o entorno sociocultural e contextual das famílias pelos profissionais de saúde - pensamento que não condiz ao talhe necessário para a atuação em Saúde da Família (Tesser, 2006; Markmann Neto, 2004), comprometendo a legitimidade do modelo de atenção, conforme a equipe ainda vivencia o modelo hegemônico e tradicional, apesar das tentativas de modificá-lo na prática, permanecendo em um estado entre a ESF idealizada e a ESF de fato (Markmann Neto, 2004).

Machado (2005) aponta fragilidades quanto ao recurso humano no SUS durante seu processo de implementação. Em relação à Saúde da Família, trabalho em equipe significa interação entre os diversos profissionais, um dos pilares deste modelo de atenção, orientado à integralidade nos cuidados de saúde pautada na relação entre a complementaridade de trabalhos e a interação dos profissionais (Araújo, Rocha, 2007; Crevelim, Peduzzi, 2005; Silva, Trad, 2005).

Para Chaves (2003), a prestação dos cuidados em saúde é um campo imanente na complexidade. Morin (2007) defende que a redução na disciplinaridade não abarca o ser humano em si, na emergência da vida individual e particular vivida no/com o coletivo - perspectiva que comporta a proposta de visão ampliada evocada pela ESF, em que a visão biomédica estrita não se mostra apropriada, assim como a formação profissional pautada por esta orientação.

Nesta perspectiva, ao adotar, a ESF, uma formulação que prima pelo atendimento integral, complexo, na multidimensionalidade humana, há necessidade de profissionais que lidem com determinantes sociais de saúde, articulando a atuação profissional de maneira intersetorial com a realidade adscrita.

Após 15 anos de implantação da ESF no Brasil, os ganhos em termos dos princípios da equidade e da universalidade mostraram-se significativos (Alves, 2005). O mesmo não pode ser afirmado sobre a consolidação do princípio da integralidade (Schimith, Lima, 2004).

Tendo em vista o contexto apresentado, e que a formação fragmentada dos profissionais de saúde pode comprometer o desempenho da Estratégia como proposta, o presente artigo tem por objetivo debater a formação do médico, do enfermeiro e do odontólogo, e sua adequação à visão ampliada de saúde implicada no SUS/ESF, pautando-se no pensamento complexo e na perspectiva dos princípios sugeridos para a prática neste modelo de atenção em equipe multiprofissional.

\section{Percurso metodológico}

O presente artigo trata de pesquisa exploratório-descritiva fundamentada na epistemologia da complexidade, referenciando-se no pensamento de Edgar Morin, focalizando-se no contexto da formação profissional do médico, enfermeiro e odontólogo na Universidade Federal do Amazonas. Primou pela análise integradora entre o empírico e sua adequação à necessidade em Saúde da Família conforme preconizado nos documentos oficiais da estratégia, o que implica uma visão do homem como ser multidimensional por parte do profissional da ESF. Dado que se trata de relação, o caminho do reducionismo apresenta calhas estreitas demais para abarcarem esta realidade da formação universitária e da adequação ao que pede o modelo de atenção, não se tratando de um contexto doseresposta. Daí a opção metodológica pelo talhe qualitativo em pesquisa (Minayo, 1999).

Faz-se mister registrar que o processo de construção histórico-social como profissão é diferente em cada uma das três formações. Mas, o SUS não deveria ser o direcionador da formação dos profissionais de saúde, conforme a Constituição brasileira preconiza? E, sendo a Atenção Primária "o contato preferencial dos usuários com os sistemas de saúde" (Brasil, 2007), a ESF não teria um caráter norteador desta formação? E, no trabalho na ESF, não está implicado projeto assistencial único e focado nas minúcias desta proposta de integração entre os diversos profissionais? 
O presente trabalho foi autorizado pelo Comitê de Ética em Pesquisa com Seres Humanos da Universidade Federal do Amazonas, sob protocolo ético CEP/UFAM/036/2006, obedecendo a todos os procedimentos preconizados nas leis brasileiras sobre pesquisa com seres humanos; sendo explicado aos acadêmicos que foram convidados em razão de se enquadrarem nos critérios de inclusão, que a participação era voluntária, que poderiam sair do estudo quando desejassem sem qualquer prejuízo. Foram explicados, também, os procedimentos referentes ao grupo focal, que estariam na presença de outras pessoas, e que, no início da reunião, seria solicitado, aos participantes, que não comentassem o conteúdo das falas dos integrantes com pessoas que não integraram o grupo; e que também poderiam se omitir, caso desejassem, no transcurso da atividade de grupo focal. Registrou-se como os dados seriam tratados e que seriam divulgados no meio científico, mas sem informações que pudessem identificar os participantes do grupo.

Em termos instrumentais, utilizou-se a técnica de grupo focal (Minayo, 1999; Morgan, 1997). Além do moderador, houve um segundo pesquisador no papel de observador. Ao término de cada grupo focal, com duração média de uma hora e meia, ambos se reuniram para discutir impressões. As questões norteadoras trabalharam: o modelo pedagógico vivenciado, a percepção sobre o que é a profissão, a atuação do profissional nos diversos níveis de atenção à Saúde e o trabalho em equipe multiprofissional. Todas as discussões foram registradas por meio de gravação com fita magnética.

Foram critérios de inclusão dos sujeitos: ser discente da Universidade Federal do Amazonas; cursar um dos cursos investigados; estar cursando o último período no ano de 2007; cursar todo o curso na mesma turma que os outros sujeitos; não ter cursado outro curso de graduação anteriormente. A inadequação a qualquer dos critérios foi considerada como único critério de exclusão.

Com relação ao recrutamento dos sujeitos, após aula regular do curso, o pesquisador explicou o projeto aos acadêmicos do último período, convidando-os a tomar parte. No entanto, de maneira similar, apenas seis acadêmicos de cada um dos cursos se dispuseram a participar do projeto. Este número de sujeitos está em conformidade com o mínimo sugerido nesta técnica de coleta de informações (Minayo, 1999; Morgan, 1997). Os grupos focais foram realizados separadamente por curso.

Tabela 1. Caracterização dos participantes da pesquisa.

\begin{tabular}{|c|c|c|c|c|c|}
\hline Sujeito & Curso & Ano de ingresso & Gênero & Idade & Estado de origem \\
\hline Sujeito 01 & Medicina & 2002 & $M$ & 27 anos & Amazonas \\
\hline Sujeito 02 & Medicina & 2002 & $\mathrm{~F}$ & 26 anos & Amazonas \\
\hline Sujeito 03 & Medicina & 2002 & $M$ & 23 anos & Goiás \\
\hline Sujeito 04 & Medicina & 2002 & $M$ & 28 anos & Amazonas \\
\hline Sujeito 05 & Medicina & 2002 & $M$ & 25 anos & Tocantins \\
\hline Sujeito 06 & Medicina & 2002 & $M$ & 23 anos & Goiás \\
\hline Sujeito 07 & Enfermagem & 2004 & $\mathrm{~F}$ & 23 anos & Ceará \\
\hline Sujeito 08 & Enfermagem & 2004 & $\mathrm{~F}$ & 22 anos & Amazonas \\
\hline Sujeito 09 & Enfermagem & 2004 & $\mathrm{~F}$ & 21 anos & Amazonas \\
\hline Sujeito 10 & Enfermagem & 2004 & $\mathrm{~F}$ & 20 anos & Amazonas \\
\hline Sujeito 11 & Enfermagem & 2004 & $\mathrm{~F}$ & 22 anos & Amazonas \\
\hline Sujeito 12 & Enfermagem & 2004 & $\mathrm{~F}$ & 21 anos & Amazonas \\
\hline Sujeito 13 & Odontologia & 2004 & $\mathrm{~F}$ & 21 anos & Amazonas \\
\hline Sujeito 14 & Odontologia & 2004 & $\mathrm{~F}$ & 22 anos & Amazonas \\
\hline Sujeito 15 & Odontologia & 2004 & $\mathrm{~F}$ & 22 anos & Amazonas \\
\hline Sujeito 16 & Odontologia & 2004 & $\mathrm{~F}$ & 24 anos & Acre \\
\hline Sujeito 17 & Odontologia & 2004 & $F$ & 23 anos & Amazonas \\
\hline Sujeito 18 & Odontologia & 2004 & $\mathrm{~F}$ & 23 anos & Amazonas \\
\hline
\end{tabular}


Todas as gravações foram transcritas na íntegra, material sob o qual se realizou leitura exaustiva para apropriação do conteúdo, seguindo o modelo para tratamento, redução e análise, conforme preconizado pela literatura (Minayo, 1999; Morgan, 1997). A análise pautou-se na hermenêutica dialética (Minayo, 2002), perspectiva adotada pela reflexão que se funda na práxis, na busca pela compreensão atrelada à análise crítica da realidade, processualmente seguindo as etapas de confrontação, convergências e divergências das categorias (Minayo, 1999). Para a interpretação, o produto final foi confrontado com o marco teórico do pensamento complexo sobre Saúde Coletiva no Brasil e sobre ESF, na busca por conteúdos coerentes, singulares ou contraditórios.

\section{Resultados}

No grupo focal com acadêmicos de Medicina, prevaleceu a visão do médico como superior aos demais profissionais, com trabalho em equipe tendo o médico como centro - justificado por estes acadêmicos devido à vastidão dos conteúdos teóricos na formação médica quando comparados aos demais profissionais -, com grande preocupação em relação ao perfeccionismo nos aspectos técnicocurativos, e visão biomédica pautada na doença. Esta perspectiva irá chocar-se com os princípios da ESF, e denuncia visão reducionista e fragmentária no que concerne ao trabalho em equipe.

É uma coisa de hierarquia, não é? Medicina é um curso só para quem pode. 'Tua mãe é técnica, tuas irmãs são enfermeiras e você é quem vai mandar.' (Sujeito 6)

Então, tem essa questão aí, de hierarquia, mas eu acredito que todo profissional de saúde tem que trabalhar de equipe. Por que se tu pedes para o outro profissional fazer, ele também vai integrar o procedimento? Isso é trabalhar em equipe. (Sujeito 1)

Acho que sem a medicina, não a odontologia, mas o trabalho da enfermagem ia ser limitado. Porque o médico aprende todos os procedimentos, agora eu acho que os procedimentos de enfermagem, todos os médicos são capazes de fazer. (Sujeito 2)

O médico entra em contato com uma carga maior de informações. (Sujeito 5)

Os outros profissionais são eficientes fazendo o trabalho complementar ao do médico. (Sujeito 2)

Ser médico é dar o melhor de si para poder tornar uma pessoa melhor naquela patologia que ela tem. (Sujeito 2)

Como o médico pode não pensar apenas na dor? O que ele pode fazer além de prescrever ou operar alguém? (Sujeito 3)

A atuação em atenção primária é caracterizada apenas no aspecto da prevenção específica. Há referência à amplitude dos determinantes de saúde, reconhecendo, de certa forma, a complexidade implicada na atenção primária, mas não operacionalizam como atuar frente a estas relações, emergindo novamente o modelo biomédico, focado, exclusivamente, em ações técnicas relacionadas à proteção específica. $\mathrm{O}$ atendimento médico é caracterizado pelo ato prescritivo, reducionista, desarticulado com a proposta da Saúde da Família e do trabalho em equipe. A atuação profissional perante o paciente limita-se a este ato, desconsiderando os aspectos sociais envolvidos em questões como o uso de medicamentos, reduzindo a atuação médica frente às possibilidades que the são implicadas no trabalho em Saúde da Família. A responsabilidade é focada no outro, seja este Estado, paciente ou demais membros da equipe.

O PSF vai ser diferente porque existe mais parte da área preventiva. (Sujeito 5) 
'Educação em Saúde' é explicar direito para o paciente como usar o remédio que a gente prescreve. (Sujeito 4)

Não se trata só da questão da doença. É a moradia, higiênico-sanitária. Neste ponto, o médico não tem como atuar. Não é responsabilidade dele. Isso é para o governo, para os profissionais da assistência social. Mas não do médico. (Sujeito 2)

Os pacientes são percebidos como pessoas sem instrução e o conhecimento médico tem o papel de esclarecê-los, de iluminá-los. A abordagem pautada no contexto cultural é, claramente, desconsiderada, tanto quanto a horizontalidade necessária ao vinculo e à corresponsabilidade entre usuário e profissional, conforme preconizado, prevalecendo a visão biomédica pautada na doença e que será reforçada na definição de 'paciente'.

Paciente é pessoa que procura serviço médico precisando de auxílio quanto ao processo saúdedoença. (Sujeito 1)

Às vezes o paciente não consegue seguir uma orientação nossa. Então não tem como tratá-lo. (Sujeito 4)

Você fala dez vezes uma coisa e o paciente não entende, porque o pobre não tem acesso à educação formal, não tem realmente como entender. (Sujeito 2)

O paciente que não tem uma boa adesão ao tratamento é um paciente problemático. Quando o paciente assume o compromisso de receber o tratamento médico, também tem que assumir o compromisso de seguir certo o que o médico fala. Porque o médico sou eu, ele tem que aceitar. (Sujeito 3)

Para o grupo de acadêmicos de Enfermagem, o enfermeiro é o centro da equipe de saúde, porque permanece mais tempo junto aos usuários e, assim, tem mais conhecimento sobre o processo saúde-doença. Esta perspectiva fere o trabalho em equipe multiprofissional, no qual todos têm igual importância apesar das diferentes competências. Apesar de ressaltarem a importância do enfermeiro na equipe de saúde, demonstram sentimento de baixa valorização da Enfermagem frente aos demais profissionais.

O enfermeiro é a pessoa mais próxima do paciente. O enfermeiro tem uma visão melhor. $\mathrm{O}$ médico fica 10 minutos frente ao paciente e você fica o dia todo. (Sujeito 8)

O enfermeiro é o coração do serviço de saúde. Interage em todas as áreas, com funcionários, faz os cuidados básicos, a comunicação com a equipe médica, a comunicação com o paciente. Todo e qualquer problema passa pelo enfermeiro. O enfermeiro sabe de tudo. (Sujeito 12)

O trabalho da equipe depende muito do enfermeiro. Depende de ele ser unido e comandar a equipe, porque se ele não comandar fica tudo bagunçado e não vai haver trabalho em equipe. (Sujeito 11)

Geralmente o médico não aceita a importância do enfermeiro. Acho que agora o enfermeiro está querendo o seu lugar. O enfermeiro não está deixando as pessoas invadirem e se intrometer no que ele faz. (Sujeito 11)

Emerge a percepção de que o atendimento em saúde na atenção primária não deve se limitar ao tratamento da doença, e que o enfermeiro deve lidar com todos os aspectos que sejam implicados na saúde do indivíduo. No entanto, silencia-se sobre a operacionalização destes conceitos teóricos, 
dando a impressão de adotarem o discurso "politicamente correto" e em consonância com princípios norteadores do SUS; mas não declaram a vinculação com a prática de Enfermagem no SUS/ESF, que é abordada, sobretudo, pelo aspecto preventivo, inclusive apresentando diferenciação entre atendimento ambulatorial e atendimento em atenção primária, resgatando o discurso preventivista de que este nível se presta somente às ações de promoção de saúde e proteção específica, o que é díspar em relação às reais atribuições deste nível de atenção.

A enfermagem não é voltada só para doença. (Sujeito 7)

Você faz saúde juntando tudo: prevenindo, educando, promovendo e reabilitando o paciente. (Sujeito 9)

Na Saúde Coletiva o profissional tem que ter conhecimento para atender a população diferente do atendimento do consultório, principalmente na prevenção. (Sujeito 10)

A área ambulatorial tem diferença para saúde publica por que nesta a gente trabalha muitas vezes com grupos, grupos da escola, grupo da comunidade. A questão é muito mais de prevenção mesmo. Já o atendimento ambulatorial não. (Sujeito 11)

Para as entrevistadas, existe relação entre a vida da comunidade e o trabalho do enfermeiro, pensando-se inclusive que, se a saúde da comunidade vai bem, é fruto do bom trabalho destes profissionais. Esta perspectiva choca-se com outra abordagem: a impotência do profissional frente a demandas sociais específicas, como a falta de alimentação e medicamento. Novamente, assumem para si a centralidade do trabalho em equipe - a equipe está na dependência do enfermeiro - e silenciam sobre o princípio da intersetorialidade, imprescindível no âmbito da ESF. Também, ao referirem respeito aos aspectos culturais da comunidade, revelam que há conflito interno entre o cuidar de enfermagem e manter a autonomia do usuário, com certa prescrição de condutas e dificuldade para manter a horizontalidade junto aos pacientes.

Se a saúde daquela comunidade estiver bem é porque o enfermeiro faz o trabalho adequado. (Sujeito 11)

Existem certas doenças que o paciente precisa ter alimentação em especial. O paciente tem a moradia totalmente precária, come hoje e não sabe se vai comer amanhã. Como ele vai comprar um remédio para gripe do filho se ele não tem roupa não tem comida entende? (Sujeito 8)

O paciente chegou à unidade de saúde com uma folha no pé, colocou uma mistura de mandioca que ele bateu. Quando eu olhei, minha vontade é pegar aquilo ali, tirar essa folha, pegar uma bacia, lavar mesmo e fizer um curativo. (Sujeito 12)

Você deve respeitar a escolha do paciente, mas também pode ir adequando paralelamente. A gente poderia instruir 'você pode colocar a folhinha, mas também pode fazer o curativo', Como isso eu não o mandei tirar a folhinha dali, mas também o instruí a fazer o nosso procedimento certo. (Sujeito 11)

Os acadêmicos de odontologia aludem à percepção ampliada e complexa da saúde em diversos momentos do discurso, mas, ao operacionalizarem conceitos, fazem dicotomia entre preventivo e curativo, associando apenas o primeiro à atenção primária. O que atribuem à visão ampliada tratase da etapa inicial da prestação de serviços odontológicos, limitando-se à anamnese, resistindo o discurso flexneriano/biomédico. O consultório odontológico é construído nas falas como território pouco articulado com a prática em Saúde Pública e, apesar do discurso de atenção ampliada, somente 
se discutem aspectos referentes à prática odontológica clínica, nem mesmo mencionando outros profissionais.

Alguns profissionais vêem o paciente sentado na cadeira odontológica e só olham para aquela área que é especialista. Isso não é correto. É lógico que tem que dar atenção maior aquela área mas na parte inicial do procedimento ele tem que ver tudo. (Sujeito 17)

A odontologia como profissão significa restabelecer a estética e também, muitas vezes, a função do paciente. Tem paciente que chega com o processo de mastigação impossibilitando comer determinados alimentos pela falta de dentes. (Sujeito 16)

O dentista não trata só a saúde bucal. Muitas vezes a gente estabelece a saúde geral do paciente porque ele chega e não tem cuidado com a boca, quanto mais com restante. (Sujeito 14)

É recorrente a idéia de que o paciente deixa a saúde de lado por opção, e não por questões socioeconômicas, inferindo-se que pacientes de estratos socioeconômicos mais baixos têm menos saúde pela deficiência em conhecimento formal. Silencia-se sobre como interferir neste processo e não se assume compromisso com esta realidade, o que contraria o enfoque preconizado na ESF. Prevalece o discurso de que o paciente não compreende o profissional de saúde e dificulta o tratamento, emergindo discurso de verticalidade na relação, o que compromete vínculo e corresponsabilidade, convergente com o achado nos acadêmicos médicos e enfermeiros.

Tem paciente que deixa a boca de lado. (Sujeito 16)

Quando você vê um paciente com falta de higiene oral também nota falta de higiene em outras partes do corpo. (Sujeito 11)

Os pacientes de classe menos favorecida apresentam condições patológicas mais sérias e mais difíceis de serem tratadas. Tudo é mais complicado, porque eles não têm conhecimento. Tem muito paciente que não procura o dentista. Só procura quando está em uma condição extrema. Diferente de um que tem um nível de conhecimento melhor. (Sujeito 14)

Paralelamente, existe um forte discurso vinculado aos determinantes sociais de saúde e da complexidade nas relações destes, mas com silêncio sobre como tornar operacionais estes conceitos, mesmo que, na ESF, abra-se margem para atuação além da clínica, na direção da prática sobre estes determinantes sociais.

Saúde coletiva é pensar no coletivo e nos programas de saúde pública como o SUS. (Sujeito 16)

É entender a saúde nos bairros, saber os enfoques daquela comunidade. Na verdade a saúde coletiva mostra a realidade mesmo na região, porque às vezes você trabalha no consultório particular e fica meio alheio a essa realidade dos pacientes que vão para você. Então saúde coletiva mostra justamente o todo. Podem ser questões ambientais ou socioeconômicas que estão interferindo para que, por exemplo, o índice de carie seja elevado. (Sujeito 13)

Sobre trabalho em equipe, referem-no, mas sem conceitos concretos de como operacionalizá-lo, ficando à margem da discussão ou, em outra medida, preocupadas em se reafirmar perante a figura do médico. O trabalho em equipe é exclusivamente a justaposição de especialidades, e não processo comum, integrado e interdisciplinar, prevalecendo o talhe flexneriano/biomédico que, reduzindo, fragmenta o indivíduo e o trabalho em saúde. 
Não só o medico é profissional de saúde. O odontólogo também é. A gente vê isso na equipe de saúde da família. (Sujeito 18)

Principalmente nos programas de saúde da família a relação entre dentista e médico é uma relação bem legal porque é uma coisa que não interfere muito na área de atuação de cada um. Apesar do enfermeiro que, querendo ou não, se sente inferior ao médico que se sente superior. (Sujeito 16)

A interação entre a equipe é importante para o paciente, também na forma de dinamizar os procedimentos e o campo de atuação. (Sujeito 13)

Há um importante foco do odontólogo priorizando o atendimento particular, considerado melhor que o atendimento público. Não discorrem sobre os motivos da falta de materiais e instrumentais nos serviços públicos de saúde, discurso frágil frente às ações coletivas e na comunidade que, ao odontólogo, são possibilitadas em Saúde da Família. Conceituam o trabalho em Saúde Pública como filantrópico, como se o odontólogo fosse remunerado apenas no consultório particular, ignorando que os usuários pagam impostos diretos e indiretos, os quais se revertem também em salários para profissionais do Serviço Público de saúde.

No consultório particular o dentista tem aquela postura de fazer um serviço de ótima qualidade porque vai receber por isso. Sabe que se tratar o paciente no serviço público, mais pacientes virá e ele está sendo mal remunerado. Com o paciente ali no serviço publico o dentista não se preocupa com o geral, quer resolver a dor e às vezes nem procura saber o que o paciente tem de verdade. (Sujeito 14)

No atendimento particular, os materiais são de melhor qualidade para que seja melhor, mais eficiente. Você faz agendamento e não passa horas em filas como o paciente do serviço público. (Sujeito 15)

É importante ressaltar que os cursos investigados estão adequados com as Diretrizes Curriculares Nacionais (DCN) nos aspectos técnicos e profissionais (Universidade Federal do Amazonas, 2006). No entanto, as formações são fragmentadas em especialidades, pouco pautadas em um sentido mais amplo, pelo enfrentamento dos determinantes sociais de saúde e no processo saúde doença, com pouca ênfase no SUS/ESF. As disciplinas que se referem a esta dimensão estão desintegradas/ dispersas ao longo do currículo, havendo pouca vivência prática em saúde na comunidade, revelando priorização da técnica e do trabalho individual focado na doença.

\section{Discussão}

Para o pensamento complexo, compreender o todo social não significa identificar características individuais, e a complexidade da realidade se faz na articulação dos indivíduos que enquanto coletividade são mais do que o agrupamento das características individuais. A retroação do todo social, produzido pela interação permanente entre seus indivíduos, interfere nas características individuais e, por conseguinte, no todo social, sendo uma perspectiva auto-organizativa das sociedades (Morin, 2001).

Encaminhando a discussão para a Saúde da Família e sua adequação ao pensamento complexo, as especialidades falham em dar conta de todas as necessidades de saúde dos indivíduos, mesmo com priorização do generalista e de saúde da família nos últimos anos, o que implica o nó crítico da formação, falhando quando os generalistas não abordam integralmente os pacientes, mas sim os "distribuem" aos especialistas (Demo, 1997). 
Apesar de os três grupos apresentaram que fazer saúde é agir além dos aspectos biomédicos, na complexidade do paciente, não mencionaram qualquer forma de operacionalizar este conceito. Outra confluência entre as três formações é a desconsideração dos conhecimentos próprios dos pacientes, discurso antagônico à relação horizontal na ESF, o que pode se dar em função de a formação dos profissionais de saúde ainda se orientar por conceitos antropológicos hegemônicos na década de 1960, em que a cultura do outro - no caso o paciente - é tomada como um saber 'exótico' ou primitivo, com supervalorização do conhecimento biomédico (Bohs, 2007).

A autoridade do profissional de saúde sobre o paciente foi aludida por todos, se manifestando, na Enfermagem, como cuidado aos pacientes - fragilizados e que desconhecem como se curar; na Medicina, como postura prescritora de padrões e atitudes saudáveis aos pacientes - que não detém o conhecimento; e, na Odontologia no, discurso de culpabilidade do paciente - pelo desconhecimento sobre saúde bucal e na centralidade do odontólogo para restabelecê-la. Relações verticalizadas, prescritoras e distantes do enfoque da ESF.

Estes achados implicam a discussão da categoria "cuidado", re-significada na literatura atual em direção às dimensões sociais e políticas, assim como o aspecto da mediação entre ajuda e poder de ajudar, implicando a questão de autonomia dos usuários (Pires, 2005). Silva et al. (2007) apresentam a dificuldade de os profissionais ouvirem as demandas dos pacientes e, por consequência, tratá-los como sujeitos - "cuidado" centrado nos protocolos de saúde, e não no usuário (Pires, 2005). Na ESF, a produção de serviços de saúde não deveria se distanciar da noção do usuário como sujeito histórico, de conhecimentos próprios e tão importantes quanto os saberes dos profissionais de saúde.

Com relação ao trabalho em equipe, os acadêmicos de Enfermagem apontaram constante batalha pela valorização e para se firmarem perante as demais profissões de saúde - o médico prevaleceu como figura central do trabalho em saúde para os acadêmicos de Medicina; enquanto os de Odontologia discorreram superficialmente, agregando os diversos profissionais em um mesmo local. Estas perspectivas são contraditórias com os princípios do trabalho efetivo em equipe, caracterizado pela interdisciplinaridade com visão crítico-social, técnica, intersubjetiva, dialógica e com o respeito ao outro, em que um profissional de saúde deve tanto se articular aos demais como promover articulação intersetorial (Figueiredo, 2006; Gattas, 2005; Schraiber et al., 1999). Este padrão está arraigado no processo de trabalho em saúde da família, podendo estar implicado no silêncio/resistência destes acadêmicos em discutirem o trabalho pela lógica da ESF (Heidemann, 2006).

A postura autoritária permeou os discursos, não apenas com relação ao paciente, mas também com a equipe, na qual o enfermeiro percebe-se como líder nas questões da gestão, o médico percebe centralidade e status frente aos demais profissionais por seu conhecimento, que julga ser maior que o dos demais. Sobre a relação entre Odontologia e as demais profissões do trabalho em equipe, houve certo silêncio nos discursos. Estas perspectivas desconsideram que a construção de um projeto comum na ESF depende não só das formas concretas de organização do trabalho, mas também da distribuição de poder na equipe (Paim apud Silva, Trad, 2005).

Aponta-se o descompasso entre as formações de Ensino Superior investigadas e a necessidade de atuação com percepção complexa do paciente nos serviços de atenção, podendo refletir fragmentação dos saberes difundidos pela Universidade e fundamentação no modelo biomédico priorizando o ensino terapêutico (Costa, 2005), seja na Enfermagem (Wynne, Brand, Smith, 1997), na Medicina (Avarenga, 2005), ou na Odontologia (Araújo, Dimenstein, 2006).

Há que se ressaltar o silêncio em documentos oficiais sobre como fazer interdisciplinaridade no trabalho em Saúde da Família, à exceção de Políticas como o HumanizaSUS (Simões et al., 2007), que se direciona ao acolhimento do usuário por todos os profissionais da equipe, priorizando seu fortalecimento e o vínculo com a comunidade.

A Educação em Saúde foi caracterizada, pelos sujeitos investigados, por palestras e a narração de conteúdos teóricos (Araújo, Dimenstein, 2006; Romão, 2007; Marco, 2006; Zanotto, Rose, 2003) apontando que a estrutura didático-pedagógica da formação universitária atual ainda se reveste de métodos tradicionalistas em detrimento de estratégias que sejam pautadas na problematização, conscientização e horizontalidade. Este modelo tradicionalista é antagônico à proposta de se abordar o ser humano em sua dimensão ampla e política, reproduzindo-se no âmbito das práticas profissionais 
em Atenção Primária (Moretti-Pires, 2008; Batista, 2006; Esperidião, 2001).

A Universidade ainda é espaço tradicionalista, descontextualizado das Políticas Públicas de Saúde e pautado no desenvolvimento cognitivo dos futuros profissionais (Esperidião, 2005), com raízes na tradição de fragmentação do conhecimento, emblematizada pelo Relatório Flexner (Yazbek et al., 2000). Na contramão deste enfoque, as DCN dos três cursos (Brasil, 2002, 2001a, 2001b) declaram-se orientadas ao modelo do SUS, havendo, atualmente, ações do Estado para reorientação da formação profissional em Saúde (Brasil, 2005).

Ainda nesta questão da formação, as DCN dos três cursos investigados primam por promover a interdisciplinaridade por meio da integração das diversas dimensões do ser humano. No entanto, as matrizes curriculares dos cursos apresentam disparidade neste aspecto; e na articulação entre universidade e serviços de atenção (Universidade Federal do Amazonas, 2006; Brasil, 2002, 2001a, 2001 b). Fica aí uma lacuna para investigações futuras.

O presente trabalho imergiu na temática da formação universitária do profissional de Saúde da Família, que, dada a complexidade, constitui apenas uma das vertentes da problemática, havendo necessidade de investigações em outros aspectos implicados, tais como o conhecimento dos professores e acadêmicos sobre as DCN e em que medida este influi em visão mais ampla ou mais reducionista dos futuros profissionais. Outra questão que fica é como os profissionais investigados articulam a formação universitária no dia-a-dia das equipes de Saúde da Família.

\section{Considerações finais}

Apesar de a Saúde da Família se constituir em um modelo de atenção primária que se distingue pela visão complexa do usuário, a formação universitária de seus profissionais ainda se pauta na visão fragmentária, reduzida ao âmbito da disciplinaridade (anatomia, patologia, genética, farmacologia, economia, sociologia etc.).

A dicotomia entre o identificar da importância e o silêncio em relação à operacionalização do trabalho em ESF pode se constituir como emblema da existência de problemas para a formação com ênfase no SUS, com os sujeitos silenciando-se sobre como atuariam adequadamente em relação aos princípios norteadores deste. Na medida em que aprenderam apenas os aspectos técnicos de sua profissão e não aprenderam como articular-se com outras profissões com que dividirão espaço nos Serviços, a enfocar a vida vivida dos pacientes e, muito menos, a intersetorialidade em Saúde, a formação universitária por si só não lhes possibilitará atuar desta forma.

E aí se põe à mesa a formação reducionista para um trabalho assumidamente complexo. As deficiências evidenciadas não se referem apenas ao debate histórico das pedagogias do "aprender fazendo" que poderia ser pensado em termos da formação do profissional de saúde propriamente dita. Antes, apontam para contextos da própria essência do processo de trabalho em Saúde da Família. Em sentido amplo, também tratam da delicada questão política própria da universidade pública brasileira: formar profissionais no âmbito de uma instituição pública com enfoque diferente da necessidade do serviço público e da coletividade. 


\section{Referências}

ALVES, V.S. Um modelo de educação em saúde para o Programa de Saúde da Família: pela integralidade da atenção e reorientação do modelo assistencial. Interface - Comunic., Saude, Educ., v.9, n.16, p.39-52, 2005.

ARAÚJO, Y.P.; DIMENSTEIN, M. Estrutura e organização do trabalho do cirurgião-dentista no PSF de municípios do Rio Grande do Norte. Cienc. Saude. Colet., v.11, n.1, p.219-27, 2006.

ARAÚJO, M.B.S.; ROCHA, P.M. Trabalho em equipe: um desafio para a consolidação da estratégia de saúde da família. Cienc. Saude Colet., v.12, n.2, p.455-64, 2007.

AVARENGA, L.M.C.A. A prática médica no programa de saúde da família e sua contribuição para mudança no modelo tecnicoassistencial em saúde: limites e possibilidades. 2005. Dissertação (Mestrado) - Faculdade de Saúde Pública, Universidade de São Paulo, São Paulo. 2005.

BATISTA, S.H.S. A interdisciplinaridade no ensino médico. Rev. Bras. Educ. Med., v.30, n.1, p.39-46, 2006.

BOEHS, A.E. et al. A interface necessária entre a enfermagem, educação em saúde e o conceito de cultura. Texto Cont. Enf., v.16, n.2, p.307-14, 2007.

BRASIL. Conselho Nacional de Educação Superior. Resolução CNE/CES 3/ 2002, de 4 de março de 2002. Institui diretrizes curriculares nacionais do curso de graduação em Odontologia. Diário Oficial da União, Brasília, DF, Seção 1. p.10.

Resolução CNE/CES 3/2001, de 9 de novembro de 2001a. Institui diretrizes curriculares nacionais do curso de graduação em Enfermagem. Diário Oficial da União, Brasília, DF, Seção 1. p.37.

Resolução CNE/CES 4/2001, de 9 de novembro de 2001b. Institui diretrizes curriculares nacionais do curso de graduação em Medicina. Diário Oficial da União, Brasília, DF, Seção 1. p.38.

Ministério da Saúde. Secretaria de Atenção à Saúde. Departamento de Atenção Básica. Política Nacional de Atenção Básica. 4. ed. Brasília: Ministério da Saúde, 2007.

Ministério da Saúde. Saúde da Família: uma estratégia para a reorientação do modelo assistencial. Brasília: DAB, 1997.

Ministério da Saúde. Ministério da Educação. Pró-saúde: programa nacional de reorientação da formação profissional em saúde. Brasília: MS/MEC, 2005.

CHAVES, M. Complexidade e transdisciplinaridade: uma abordagem multidimensional do setor saúde. Rede CEDROS, 2003. Disponível em < http://www.ufrrj.br/leptrans>. Acesso em: 2 set. 2008.

COSTA, A.S.S.M. A construção do saber da enfermeira na equipe interdisciplinar de serviço de atenção psicossocial. 2005. Tese (Doutorado) - Escola de Enfermagem, Universidade de São Paulo, São Paulo. 2005.

CREVELIM, M.A.; PEDUZZI, M. A participação da comunidade na equipe de saúde da família. Como estabelecer um projeto comum entre trabalhadores e usuários? Cienc. Saude Colet., v.10, n.2, p.323-31, 2005.

DEMO, P. Conhecimento moderno. Petrópolis: Vozes, 1997.

ESPERIDIÃO, E. Repensando a formação do enfermeiro: o processo de conscientização crítica e práticas docentes à luz do referencial ético-humanista. 2005. Tese (Doutorado) Escola de Enfermagem de Ribeirão Preto, Universidade de São Paulo, Ribeirão Preto. 2005.

Holismo só na teoria: a trama dos sentimentos do acadêmico de enfermagem sobre sua formação. 2001. Dissertação (Mestrado) - Escola de Enfermagem de Ribeirão Preto, Universidade de São Paulo, Ribeirão Preto. 2001. 
FIGUEIREDO, J.S. Desafios e perspectivas em atividades educativas de promoção de saúde de um grupo de portadores de hipertensão arterial, sob o paradigma da interdisciplinaridade. 2006. Tese (Doutorado) - Escola de Enfermagem de Ribeirão Preto, Universidade de São Paulo, Ribeirão Preto. 2006.

GATTÁS, M.L.B. Interdisciplinaridade em cursos de graduação na área da saúde da Universidade de Uberaba - UNIUBE. 2005. Tese (Doutorado) - Escola de Enfermagem de Ribeirão Preto, Universidade de São Paulo, Ribeirão Preto. 2005.

HEIDEMANN, I.T.S.B. A promoção de saúde e a concepção dialógica de Freire: possibilidades de sua inserção e limites no processo de trabalho das equipes de Saúde da Família. 2006. Tese (Doutorado) - Escola de Enfermagem de Ribeirão Preto, Universidade de São Paulo, Ribeirão Preto. 2006.

KOIFMAN, L. O modelo biomédico e a reformulação do currículo médico da Universidade Federal Fluminense. Hist. Cienc. Saude - Manguinhos, v.8, n.1, p.48-70, 2001.

MACHADO, M.H. Trabalhadores da saúde e sua trajetória na reforma sanitária. In: LIMA, N.T. et al. (Orgs.). Saúde e democracia: história e perspectivas do SUS. Rio de Janeiro: Fiocruz, 2005. p.257-81.

MARCO, M.A. Do modelo biomédico ao modelo biopsicossocial: um projeto de educação permanente. Rev. Bras. Educ. Med., v.30, n.1, p.60-72, 2006.

MARKMAN NETO, L. Políticas de Saúde, Sistema Único de Saúde e a prática do Programa de Saúde da Família num núcleo específico: limites e desafios. 2004. Dissertação (Mestrado) - Faculdade de Medicina de Ribeirão Preto, Universidade de São Paulo, Ribeirão Preto. 2004

MENDONÇA, M.H.M.; VANCONCELLOS, M.M.; VIANNA, A.L.A. Atenção Primária à Saúde no Brasil. Cad. Saude Publica, n.24, sup1, p.S4-S5, 2008.

MINAYO, M.C.S. Hermenêutica-dialética como caminho do pensamento social. In: MINAYO, M.C.S.; DESLANDES, S.F. (Orgs.). Caminhos do pensamento: epistemologia e método. Rio de Janeiro: Fiocruz, 2002. p.83-107.

O desafio do conhecimento: pesquisa qualitativa em saúde. Rio de Janeiro: Hucitec/Abrasco, 1999.

MORETTI-PIRES, R.O. O pensamento crítico social de Paulo Freire sobre humanização e o contexto da formação do enfermeiro, do médico e do odontólogo. 2008. Tese (Doutorado) - Escola de Enfermagem de Ribeirão Preto, Universidade de São Paulo, Ribeirão Preto. 2008.

MORGAN, D. Focus group as qualitative research. Boston: Sage Publications, 1997.

MORIN, E. Sobre la interdisciplinariedad. Disponível em: <www.pensamientocomplejo. com.ar> Acesso em: 2 set. 2008.

Introdução ao pensamento complexo. Porto Alegre: Ed. Sulina, 2007.

Ciência com consciência. Rio de Janeiro: Bertrand Brasil, 2001.

Epistemologia da complexidade. In: SCHNITMAN, D.F. (Org.). Novos

paradigmas, cultura e subjetividade. Porto Alegre: Artes Médicas, 1996. p.274-86.

PADILHA, P.R. Currículo intertranscultural. São Paulo: Cortez, 2004.

PIRES, M.R.G.M. Politicidade do cuidado e avaliação em saúde: instrumentalizando o resgate da autonomia de sujeitos no âmbito de programas e políticas de saúde. Rev. Bras. Saude Matern. Infant., v.5, supl1, p.S71-S81, 2005.

ROMÃO, J.E. Pedagogia dialógica. São Paulo: Cortez, 2007.

SCHIMITH, M.D.; LIMA, M.A.D.S. Acolhimento e vínculo em uma equipe do Programa Saúde da Família. Cad. Saude Publica, v.20, n.6, p.1487-94, 2004. 
SCHRAIBER, L.B. et al. Planejamento, gestão e avaliação em saúde: identificando problemas. Cienc. Saude Coletiva, v.4, n.2, p.221-42, 1999.

SILVA JR, A.G.; MERHY, E.E.; CARVALHO, L.C. Refletindo sobre o ato de cuidar da Saúde. In: PINHEIRO, R.; MATTOS, R.A. (Orgs.). Construção da integralidade: cotidiano, saberes e práticas em saúde. Rio de Janeiro: UERJ, IMS, Abrasco, 2007. p.115-30.

SILVA, I.Z.Q.J.; TRAD, L.A.B. O trabalho em equipe no PSF: investigando a articulação técnica e a interação entre os profissionais. Interface - Comunic., Saude, Educ., v.9, n.16, p.25-38, 2005.

SIMÕES, A.L.A. et al. Humanização na saúde: enfoque na atenção primária. Texto Contexto Enferm., v.16, n.3, p.439-44, 2007.

TESSER, C.D. Medicalização social (II): limites biomédicos e propostas para a clínica na atenção básica. Interface - Comunic., Saude, Educ., v.10, n.20, p.347-62, 2006.

UNIVERSIDADE FEDERAL DO AMAZONAS. Pró-Reitoria de Ensino de Graduação. Departamento de Ação Pedagógica. Matrizes curriculares dos cursos de Medicina, Enfermagem e Odontologia, com finalidade de pesquisa. Memorando 048/2006.

WYNNE, N.; BRAND, S.; SMITH, R. Incomplete holism in pre-registration nurse education: the position of the biological sciences. J. Advanc. Nurs., v.26, n.1, p.470-4, 1997.

YAZBEK, D.C.M. et al. Novos rumos para a educação médica. Rev. Bras. Educ. Med., v.24, n.2, p.26-8, 2000.

ZANOTTO, M.A.C.; ROSE, T.M.S. Problematizar a própria realidade: análise de uma experiência de formação continuada. Educ. Pesq., v.29, n.1, p.45-54, 2003.

MORETTI-PIRES, R. O. Complejidad en la Salud de la Familia y formación del futuro profesional de la salud. Interface - Comunic., Saude, Educ., v.13, n.30, p.153-66, jul./ set. 2009.

Las características del Sistema Único de Salud (SUS) y de la Estrategia de Salud de la Familia (ESF) aproximan al pensamiento complejo, término que no se refiere a la adjetivación de fenómeno de aspectos múltiplos y si al marco teórico-epistemológico. Dados los indicios de la formación inadecuada de profesionales de la salud para la actuación en ESF, se apuntó a elevar la formación de estos profesionales con el abordaje ampliado de salud implicado en el SUS/ESF, utilizándose grupos focales con académicos de Enfermería, Medicina y Odontología de la Universidad Federal de Amazonas, tratados por una perspectiva hermenéutica dialéctica. Los datos apuntaron a una formación reduccionista/biomédica en las tres profesiones así como foco en el trabajo individual y no en equipo multiprofesional, cuadro inadecuado al SUS/ESF, que preconiza la actuación profesional enfocada en la complejidad del entorno socioeconómico de los usuarios.

Palabras clave: Formación de recursos humanos en salud. Atención primaria en salud. Teoría de la complejidad. 